\title{
The surgical treatment of non-metastatic melanoma in a Clinical National Melanoma Registry Study Group (CNMR): a retrospective cohort quality improvement study to reduce the morbidity rates
}

Antonella Vecchiato $^{1 \dagger}$, Simone Mocellin ${ }^{1,2}$, Paolo Del Fiore ${ }^{1 *+}$ (O), Giulio Tosti ${ }^{3}$, Paolo A. Ascierto ${ }^{4}$, Maria Teresa Corradin ${ }^{5}$, Vincenzo De Giorgi ${ }^{6}$, Giuseppe Giudice ${ }^{7}$, Paola Queirolo ${ }^{8}$, Caterina Ferreli ${ }^{9}$, Marcella Occelli ${ }^{10}$, Monica Giordano ${ }^{11}$, Giusto Trevisan ${ }^{12}$, Luigi Mascheroni ${ }^{13}$, Alessandro Testori ${ }^{14}$, Romina Spina ${ }^{1}$, Alessandra Buja ${ }^{15}$, Francesco Cavallin ${ }^{16+}$, Corrado Caracò ${ }^{17}$, Antonio Sommariva ${ }^{18+}$, Carlo Riccardo Rossi ${ }^{1,2}$ on behalf of the Clinical National Melanoma Registry Study Group at the Italian Melanoma Intergroup (IMI)

\footnotetext{
Abstract

Background: Reproducible, high-quality surgery is a key point in the management of cancer patients. Quality indicators for surgical treatment of melanoma has been presented with benchmarks but data on morbidity are still limited. This study presents the quality indicators on morbidity after surgical treatment for non-metastatic skin melanoma in an Italian registry.

Methods: Data were extracted from the Central National Melanoma Registry (CNMR) promoted by the Italian Melanoma Intergroup (IMI). All surgical procedures (WE, SNLB or LFND) for non-metastatic skin melanoma between January 2011 and February 2017 were evaluated for inclusion in the study. Only centers with adequate completeness of information (> 80\%) were included in the study. Short-term complications (wound infection, dehiscence, skin graft failure and seroma) were investigated.

Results: Wound infection rate was 1.1\% (0.4 to 2.7\%) in WE, 1.3\% (0.7 to 2.5\%) in SLNB and $4.1 \%$ (2.1 to 8.0\%) in LFND. Wound dehiscence rate was $2.0 \%$ (0.8 to $5.1 \%)$ in WE, $0.9 \%$ (0.2 to $3.0 \%)$ in SLNB and $2.8 \%$ (0.9 to $8.6 \%)$ in LFND. Seroma rate was $4.2 \%$ (1.5 to $11.1 \%$ ) in SLNB and $15.1 \%$ (4.6 to $39.9 \%$ ) in LFND. Unreliable information was found on skin graft failure.

\footnotetext{
* Correspondence: paolo.delfiore@iov.veneto.it

${ }^{\dagger}$ Antonella Vecchiato, Paolo Del Fiore, Francesco Cavallin and Antonio Sommariva contributed equally to this work

${ }^{1}$ Surgical Oncology Unit, Veneto Institute of Oncology IOV - IRCCS, Padova, Italy

Full list of author information is available at the end of the article
}

(c) The Author(s). 2021 Open Access This article is licensed under a Creative Commons Attribution 4.0 International License, which permits use, sharing, adaptation, distribution and reproduction in any medium or format, as long as you give appropriate credit to the original author(s) and the source, provide a link to the Creative Commons licence, and indicate if changes were made. The images or other third party material in this article are included in the article's Creative Commons licence, unless indicated otherwise in a credit line to the material. If material is not included in the article's Creative Commons licence and your intended use is not permitted by statutory regulation or exceeds the permitted use, you will need to obtain permission directly from the copyright holder. To view a copy of this licence, visit http://creativecommons.org/licenses/by/4.0/ The Creative Commons Public Domain Dedication waiver (http://creativecommons.org/publicdomain/zero/1.0/) applies to the data made available in this article, unless otherwise stated in a credit line to the data. 
(Continued from previous page)

Conclusions: Our findings contribute to available literature in setting up the recommended standards for melanoma centers, thus improving the quality of surgery offered to patients. A consensus on the core issues around surgical morbidity is needed to provide practical guidance on morbidity prevention and management.

Keywords: Melanoma, Melanoma morbidity, Skin Cancer, Melanoma morbidity, Melanoma surgical treatment, Melanoma quality improvement

\section{Background}

Worldwide, 287,723 new cases of cutaneous melanoma are diagnosed each year, causing the death of 60,712 patients [1]. In non-metastatic melanoma (i.e. without clinically evident regional lymph node or distant metastasis), surgery is the mainstay of treatment [2]. The surgical strategy involves a combination of wide excision (WE), sentinel lymph node biopsy (SLNB) and radical lymph node dissection (LFND), according to cancer staging. WE can be virtually part of the surgical management of all patients with skin melanoma, SNLB is recommended based on the primary tumor thickness and LFND may be required in patients with positive sentinel node [3].

Reproducible, high-quality surgery is a key point in the management and prognosis of cancer patients $[4,5]$. When a standardized surgical procedure is established, a cyclic audit (including collection, analysis and feedback of both procedural and outcome data) allows for monitoring and improving the quality of surgery. However, cancer surgery is not always standardized, thus limiting the application of such approach [6].

While quality of surgery has been already investigated in other cancers, the use of measures of quality assurance for surgery is less established in melanoma [6]. Available literature offers substantial heterogeneity in surgical procedures among melanoma centers or even among surgeons within the same center [7]. Although adherence to current standards is part of a quality assurance process, the spreading of clinical practice guidelines is not sufficient per se to warrant homogeneity and quality of surgical treatment [8]. There is a growing interest in the implementation of a quality assurance program that includes a quantitative analysis of a set of quality indicators, such as those that can be extracted from electronic medical records [6].

Since 2014, the Italian Melanoma Intergroup (IMI) has been promoting the standardization and quality control of surgical treatment of stage I-III melanoma in Italy [9]. The IMI achieved an expert consensus on surgical treatment of melanoma, defining a list of quality indicators (detection rate, false negative rate, minimum number of excised lymph nodes, postoperative morbidity and local recurrence) with reference to benchmark values, which could be the basis for a standardized quality assurance program in Italy [10]. While quality indicators for detection rate, false negative rate and minimum number of excised lymph nodes were presented for the Central National Melanoma Registry (CNMR), data on morbidity were still pending and data on recurrence are waiting for adequate follow-up [10].

The present study focuses on evaluation of the quality indicators about morbidity after surgical treatment for non-metastatic skin melanoma.

\section{Methods}

This is a prospective multicenter study on postoperative morbidity after surgical treatment for non-metastatic skin melanoma. Data were extracted from the Central National Melanoma Registry (CNMR), which is a prospectively maintained national database for melanoma treatment promoted by the IMI in 43 melanoma centers in Italy [9]. The study was conducted according to Helsinki Declaration principles and was approved by the Ethics Committee of the Central National Melanoma Registry (CNMR). All patients gave their consent to have their data collected for scientific purpose.

The following short-term (within 30 days after surgery) complications were investigated: infection, dehiscence, skin necrosis after WE; infection, dehiscence and seroma after SLNB or LFND. Complications were defined using the National Cancer Institute Common Terminology Criteria for Adverse Events v4.0 [11]. Wound infection was defined as a disorder characterized by an infectious process involving the wound. Wound dehiscence was defined as a finding of separation of the approximated margins of a surgical wound. Skin necrosis was defined as a death of cells in living tissue caused by external factors such as infection, trauma, or bacterial agents. Seroma was defined as finding of a collection of serum in the tissues. Patient demographics were also collected.

All surgical procedures (WE, SNLB or LFND) for nonmetastatic skin melanoma between January 2011 and February 2017 were evaluated for inclusion in the study. Only centers with adequate completeness of information (> 80\%) were included in the study (11 centers for analysis of morbidity after WE; 14 centers for analysis of morbidity after SNLB; 11 centers for analysis of morbidity after LFND). Within selected centers, patients with 
pending information on morbidity and those with unfilled form were excluded from the analysis. Patient selection is shown in Supplementary Figs. 1, 2 and 3.

Statistical analysis was conducted using R 3.5 (R Foundation for Statistical Computing, Vienna, Austria) [12]. Categorical data were expressed as number and percentage, and continuous data as median and interquartile range (IQR). The morbidity rate was pooled among centers using a generalized linear mixed-effects model (with the center as random effect). The $\mathrm{I}^{2}$ value was used to investigate heterogeneity, and meta-regression was used to explore the role of center size and groin site on heterogeneity. A $p$-value less than 0.05 was considered statistically significant.

\section{Results}

\section{Wide excision}

The analysis included 3118 patients (1647 males and 1471 females) who underwent WE in 11 centers (median 246 patients/center; min 90 patients/center, $\max 650$ patients/center). Median age was 57 years (IQR 45-70) and median BMI was $24.8 \mathrm{~kg} / \mathrm{m}^{2}$ (IQR 22.4-27.5). Comorbidities were present in 459 patients (15.1\%), while the information was not available in 80 patients. Overall, median Charlson Comorbidity Index was 2 (IQR 0-3).

Wound infection occurred in 44 patients and dehiscence in 100. The information on skin graft failure was not reliable due to the non-negligible number of unfilled forms $(21 \%)$.

The proportion of patients developing wound infection ranged from 0.002 to 0.167 among centers, with a pooled proportion of 0.011 (95\% CI 0.004 to 0.027 ) (Fig. 1). Heterogeneity was high $\left(\mathrm{I}^{2}=87 \%\right)$ and center size ( $>200$ vs. $<200$ patients) was found to have a significant contribution to heterogeneity $(p<0.0001)$. Summary estimates of proportion of patients developing wound infection were 0.051 (95\% CI 0.021 to $0.121 ; \mathrm{I}^{2}=$ $80 \%)$ in centers with low size $(<200$ patients) and 0.006 (95\% CI 0.003 to $\left.0.009 ; \mathrm{I}^{2}=0 \%\right)$ in centers with large size (> 200 patients).

The proportion of patients developing dehiscence ranged from 0.005 to 0.533 among centers, with a pooled proportion of 0.020 (95\% CI 0.008 to 0.051 ) (Fig. 1). Heterogeneity was high $\left(\mathrm{I}^{2}=93 \%\right)$ and center size (> 100 vs. $<$ 100 patients) was found to have a significant contribution to heterogeneity $(p<0.0001)$. Summary estimate of proportion of patients developing dehiscence was 0.016 (95\% CI 0.010 to $\left.0.024 ; \mathrm{I}^{2}=54 \%\right)$ in centers with large size (> 100 patients) and 0.533 (95\% CI 0.425 to 0.639 ) in the only center with low size ( $<100$ patients).

\section{Sentinel lymph node biopsy}

The analysis included 1853 patients (993 males and 860 females) who underwent SLNB in 14 centers (median 98 patients/center; min 24 patients/center, $\max 338$ patients/center). SLNB site was axilla (1058 patients, $57.1 \%)$, neck (163 patients, $8.8 \%$ ) or groin (632 patients, $34.1 \%$ ). Median age was 57 years (IQR 45-69) and median BMI was $25.1 \mathrm{~kg} / \mathrm{m}^{2}$ (IQR 22.7-28.0). Comorbidities were present in 304 patients $(16.7 \%)$, while the information was not available in 40 patients. Overall, median Charlson Comorbidity Index was 1 (IQR 0-3).

Early wound complications occurred in 176 patients, including 29 wound infections, 39 dehiscences and 139 seromas (not mutually exclusive).

The proportion of patients developing early wound complications ranged from 0.007 to 0.831 among centers. Summary estimate of proportion of patients developing early wound complications after SLNB was 0.069 (95\% CI 0.030 to 0.150 ) (Fig. 2). Heterogeneity was high $\left(\mathrm{I}^{2}=94 \%\right)$; neither center size $(p=0.11)$ or rate of groin sites among SLNBs $(p=0.84)$ were not found to have a significant contribution to heterogeneity.

The proportion of patients developing wound infection ranged from 0.005 to 0.104 among centers. Summary estimate of proportion of patients developing wound infection after SLNB was 0.013 (95\% CI 0.007 to 0.025 ) (Fig. 2). Heterogeneity was moderate $\left(\mathrm{I}^{2}=60 \%\right)$; neither center size $(p=0.25)$ or rate of groin sites among SLNBs $(p=0.60)$ were not found to have a significant contribution to heterogeneity.

The proportion of patients developing dehiscence ranged from 0.005 to 0.101 among centers. Summary estimate of proportion of patients developing dehiscence after SLNB was 0.009 (95\% CI 0.002 to 0.030) (Fig. 2). Heterogeneity was high $\left(\mathrm{I}^{2}=88 \%\right)$; neither center size $(p=0.98)$ or rate of groin sites among SLNBs $(p=0.89)$ were not found to have a significant contribution to heterogeneity.

The proportion of patients developing seroma ranged from 0.004 to 0.792 among centers. Summary estimate of proportion of patients developing seroma after SLNB was 0.042 (95\% CI 0.015 to 0.111 ) (Fig. 2). Heterogeneity was high $\left(\mathrm{I}^{2}=95 \%\right)$; neither center size $(p=0.10)$ or rate of groin sites among SLNBs $(p=0.45)$ were not found to have a significant contribution to heterogeneity.

\section{Radical lymph node dissection}

The analysis included 502 patients (301 males and 201 females) who underwent LFND in 11 centers (median 25 patients/center; min 15 patients/center, max 138 patients/center). LFND site was axilla (276 patients, $55.0 \%$ ), neck (60 patients, $12.0 \%$ ) or groin (166 patients, $33.0 \%$ ). Median age was 59 years (IQR 47-70) and median BMI was $25.5 \mathrm{~kg} / \mathrm{m}^{2}$ (IQR 22.9-28.6). Comorbidities were present in 93 patients $(19.0 \%)$, while the information was not available in 12 patients. Overall, median Charlson Comorbidity Index was 2 (IQR 0-3). 


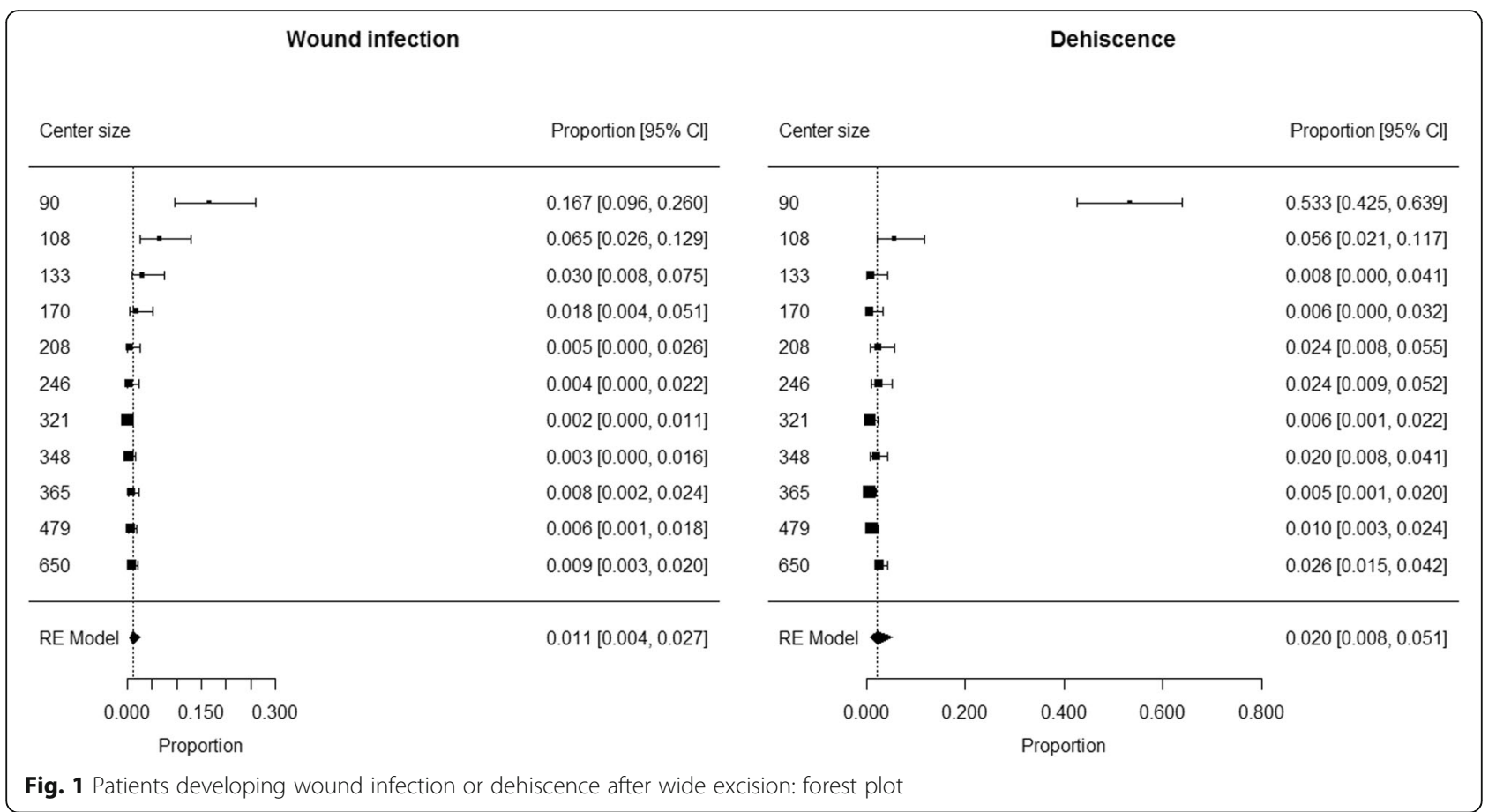

Early wound complications occurred in 98 patients, including 22 wound infections, 27 dehiscences and 85 seromas (not mutually exclusive).

The proportion of patients developing early wound complications ranged from 0.024 to 0.969 among centers. Summary estimate of proportion of patients developing early wound complications after LFND was 0.195 (95\% CI 0.068 to 0.447 ) (Fig. 3). Heterogeneity was high $\left(\mathrm{I}^{2}=94 \%\right)$; neither center size $(p=$ $0.08)$ or rate of groin sites among LFNDs $(p=0.41)$ were not found to have a significant contribution to heterogeneity.

The proportion of patients developing wound infection ranged from 0.006 to 0.58 among centers. Summary estimate of proportion of patients developing wound infection after SLNB was 0.041 (95\% CI 0.021 to 0.080) (Fig. $3)$. Heterogeneity was moderate $\left(\mathrm{I}^{2}=54 \%\right)$; neither center size $(p=0.07)$ or rate of groin sites among SLNBs $(p=0.53)$ were not found to have a significant contribution to heterogeneity.

The proportion of patients developing dehiscence ranged from 0.006 to 0.244 among centers. Summary estimate of proportion of patients developing dehiscence after SLNB was 0.028 (95\% CI 0.009 to 0.086) (Fig. 3). Heterogeneity was high $\left(\mathrm{I}^{2}=80 \%\right)$; neither center size $(p=0.38)$ or rate of groin sites among SLNBs $(p=0.14)$ were not found to have a significant contribution to heterogeneity.

The proportion of patients developing seroma ranged from 0.021 to 0.969 among centers. Summary estimate of proportion of patients developing seroma after SLNB was 0.151 (95\% CI 0.046 to 0.399) (Fig. $3)$. Heterogeneity was high $\left(\mathrm{I}^{2}=95 \%\right)$; neither center size $(p=0.18)$ or rate of groin sites among SLNBs $(p=0.29)$ were not found to have a significant contribution to heterogeneity.

\section{Discussion}

This study reported the morbidity rates in the largest series of non-metastatic melanoma patients in Italy and one of the largest series worldwide. The present work allowed to evaluate standardization and quality of surgical treatment of cutaneous melanoma within the frame of the Italian Melanoma Intergroup, which is the largest Italian scientific organization dedicated to the management of patients with this disease [10].

The occurrence of wound dehiscence and seroma after SLNB or LFND were in broad agreement with previous studies [13-15] (Table 1), thus suggesting limited opportunities for further improvements now. Such rates can be used as morbidity benchmarks in addition to available quality indicators for surgical treatment of melanoma [10].

Interestingly, we found lower occurrence of wound infection after WE or LFND when compared to available literature [13] (Table 1). On one hand, this difference might be partially due to different definitions of wound infection, i.e. presence of fever, only skin redness, suppuration versus cellulitis, isolation of bacteria from wound. On the other hand, some factors might have led 
Early wound complications

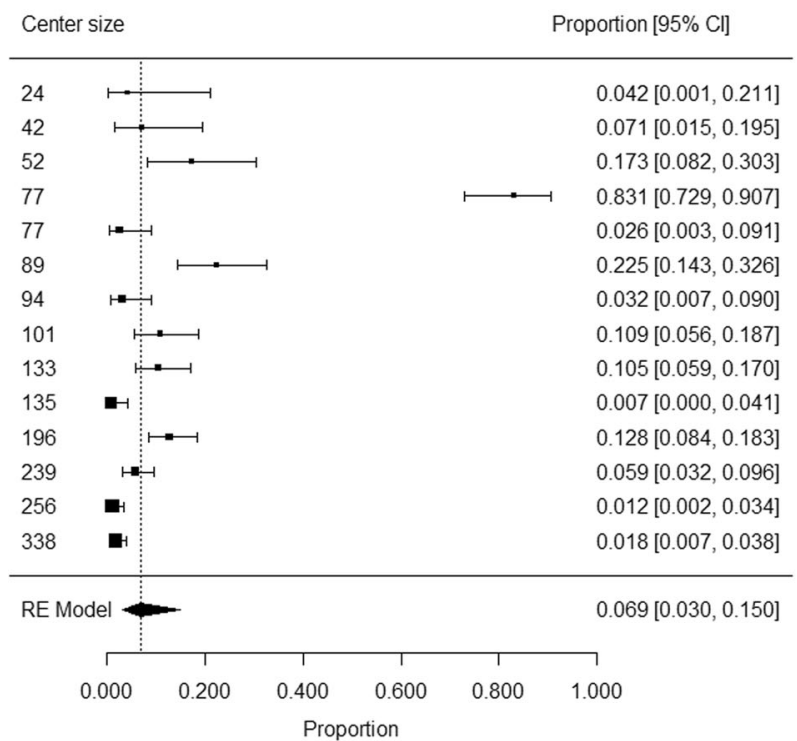

Dehiscence

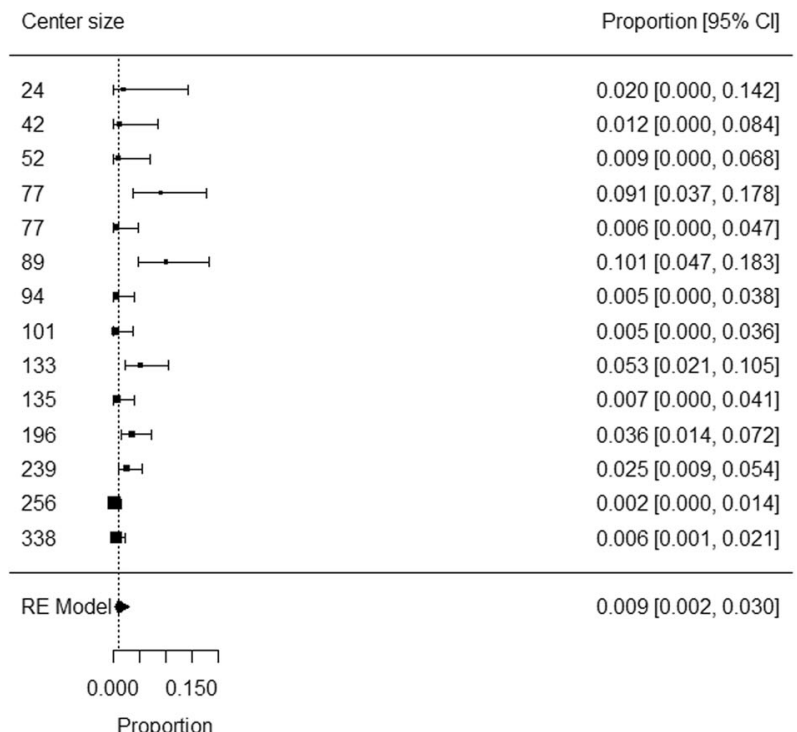

Wound infection

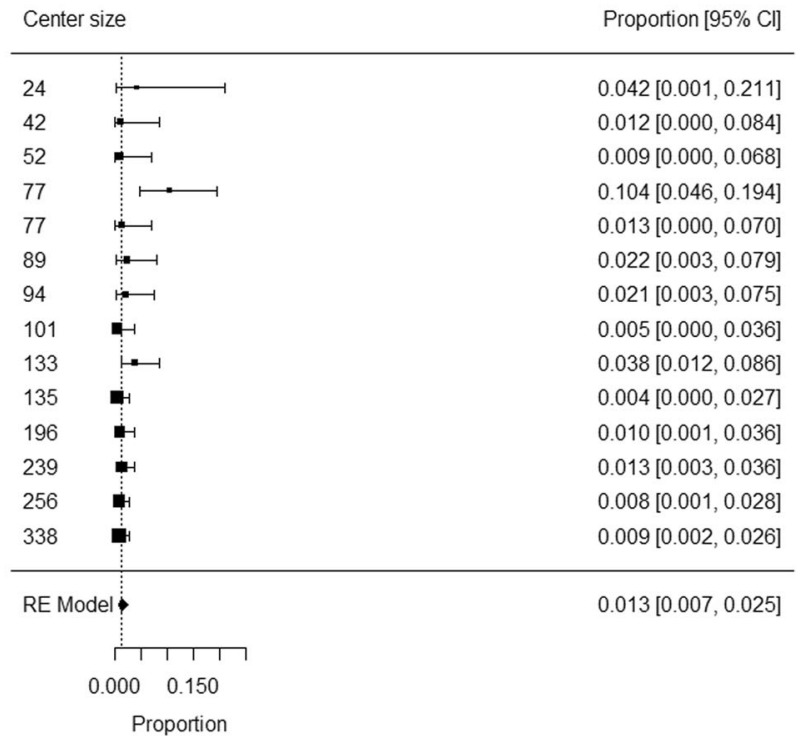

Seroma

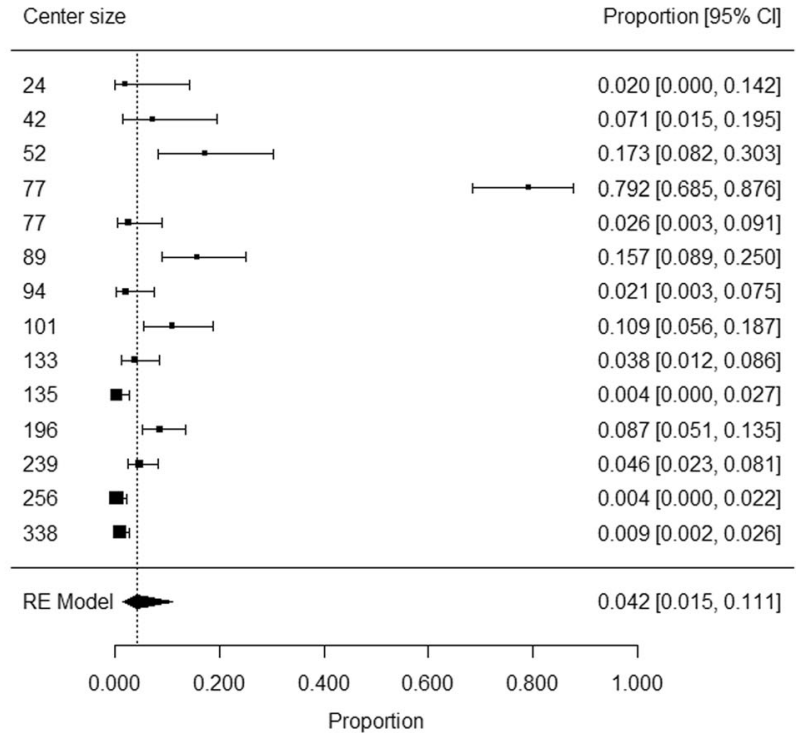

Fig. 2 Patients developing early wound complications, wound infection, dehiscence and seroma after SLNB: forest plot

to such difference, including: i) recording of infections occurring only during hospital stay or also at the time of outpatient department visits; ii) different frequency/type of antibiotic prophylaxis; iii) different surgical techniques (i.e., use, type and duration of permanence of drainages in the surgical wound).

Postoperative infections account for around one out of four complications associated with hospitalrelated health care procedures, and can impair patient prognosis [16]. Beyond clinical importance, a low infection rate can also have an economic impact, since the management of hospital-related infections requires about $0.8 \%$ of gross domestic product (GDP) in Italy [17].

Unfortunately, the information on skin graft failure was not reliable because one out of five forms did not report such complication. This situation likely occurred because skin graft failure required a reconstructive 


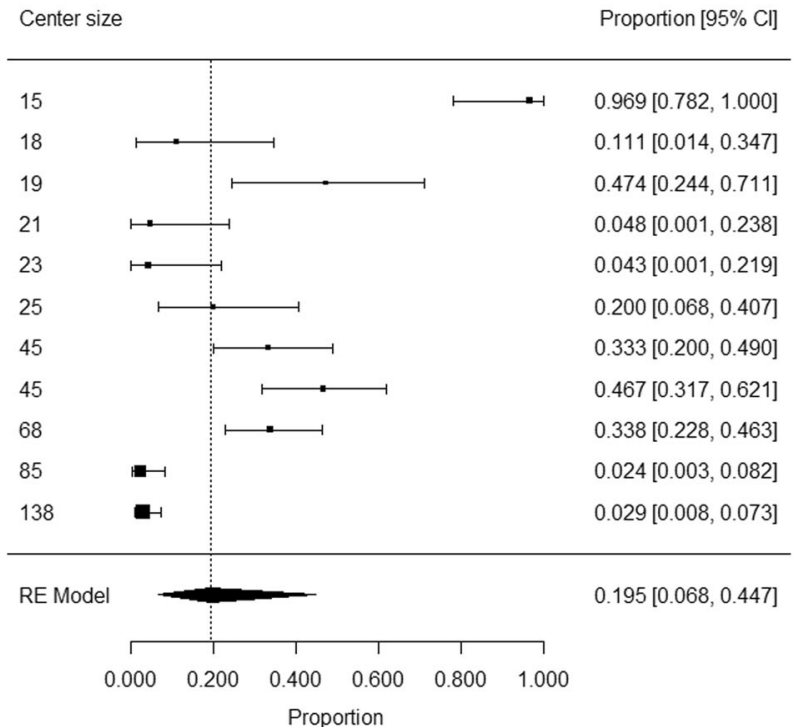

Dehiscence

\section{Center size}

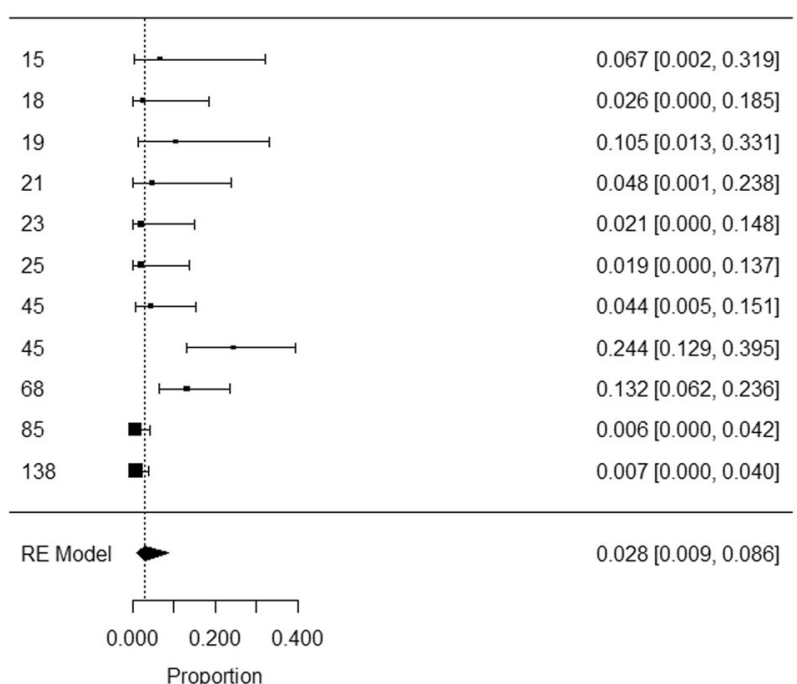

Wound infection

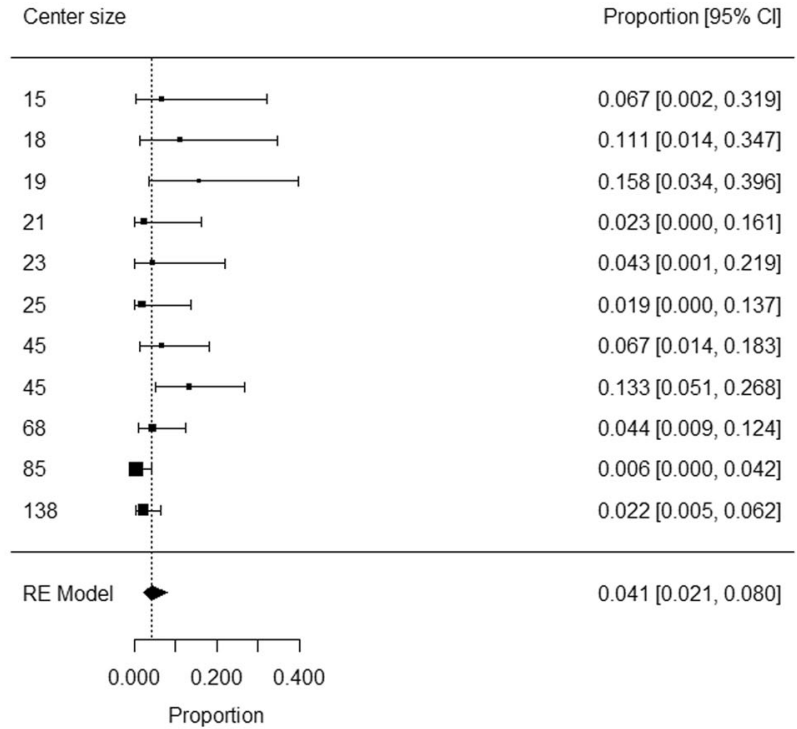

Seroma

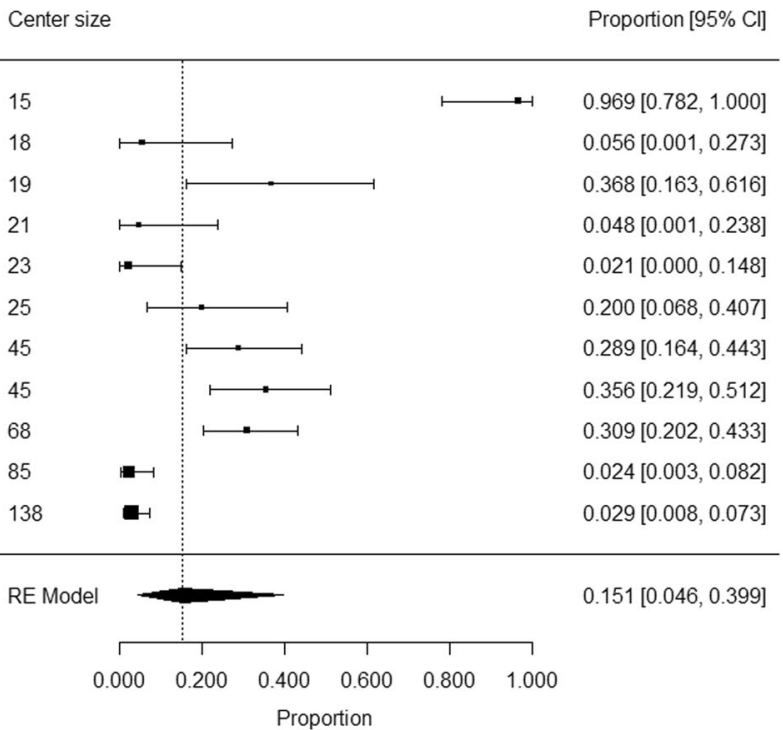

Center size

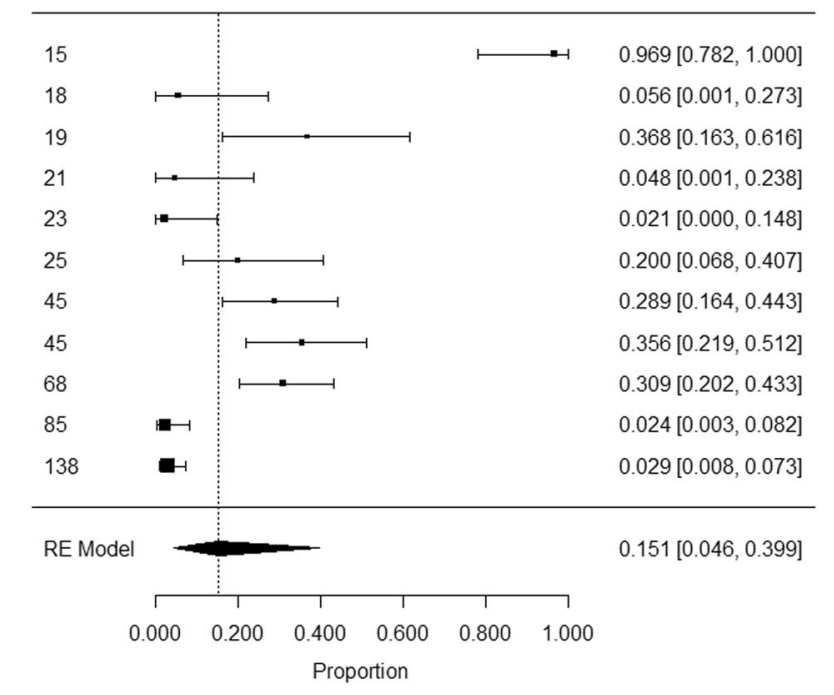

Fig. 3 Patients developing early wound complications, wound infection, dehiscence and seroma after LFND: forest plot

surgical management that several centers demanded to a different surgical unit. This situation may be addressed by improving the information exchange among surgical centers involved in patient care.

Of note, morbidity rates showed high heterogeneity across melanoma centers, underlying the role of the center itself on this matter. Our data suggested an association between higher morbidity rate and small-volume centers, thus confirming the relationship between patient outcome and hospital surgical volume [18].

The present study contributes to the definition of quality indicators for surgical treatment for nonmetastatic skin melanoma, by adding morbidity indicators that can be used as the basis for a standardized quality assurance program [10]. The importance of this topic relies on the large number of surgical 
Table 1 Referral values for morbidity rate in the IMI-CNMR study and in the international

\begin{tabular}{|c|c|c|c|}
\hline \multirow{2}{*}{$\begin{array}{l}\text { Surgical } \\
\text { Procedure }\end{array}$} & \multirow[t]{2}{*}{ Indicators } & \multicolumn{2}{|c|}{ Benchmark referral values } \\
\hline & & Present study & $\begin{array}{l}\text { International } \\
\text { literature }\end{array}$ \\
\hline \multirow[t]{3}{*}{ WE } & Wound infection & $1.1 \%$ (0.4 to $2.7 \%)$ & $4.6-8.4 \%^{a}$ \\
\hline & Wound dehiscence & $2.0 \%$ (0.8 to $5.1 \%)$ & $3.5-4.6 \%^{\mathrm{a}}$ \\
\hline & Skin graft failure & unreliable & $<2 \%^{\mathrm{a}}$ \\
\hline \multirow[t]{3}{*}{ SLNB } & Wound Infection & $1.3 \%$ (0.7 to $2.5 \%)$ & $2.9 \%(1.5 \text { to } 4.6 \%)^{b}$ \\
\hline & Wound dehiscence & $0.9 \%$ (0.2 to $3.0 \%)$ & $0.24-1.2 \%^{\mathrm{a}}$ \\
\hline & Seroma & $4.2 \%(1.5$ to $11.1 \%)$ & $5.1 \%(2.5 \text { to } 8.6 \%)^{b}$ \\
\hline \multirow[t]{4}{*}{ LFND } & Wound infection & $4.1 \%$ (2.1 to $8.0 \%)$ & $15.8 \%^{\mathrm{a}}$ \\
\hline & Wound dehiscence & $2.8 \%(0.9$ to $8.6 \%)$ & $3 \%^{a}$ \\
\hline & Wound infection and/or dehiscence & $6.5 \%$ (2.9 to $14.0 \%)$ & $21.6 \%(13.8 \text { to } 30.6 \%)^{c}$ \\
\hline & Seroma & $15.1 \%$ (4.6 to $39.9 \%)$ & $17.9 \%(10.3 \text { to } 27 \%)^{c}$ \\
\hline
\end{tabular}

Data expressed as percentage with $95 \%$ confidence interval in parentheses

${ }^{a}$ Morton DL, Cochran AJ, Thompson JF, Elashoff R, Essner R, Glass EC, Mozzillo N, Nieweg OE, Roses DF, Hoekstra HJ, Karakousis CP, Reintgen DS, Coventry BJ, Wang HJ; Multicenter Selective Lymphadenectomy Trial Group. Sentinel node biopsy for early-stage melanoma: accuracy and morbidity in MSLT-I, an international multicenter trial. Ann Surg. 2005 Sep;242 (3):302-11; discussion 311-3

${ }^{\mathrm{b}}$ Moody JA, Ali RF, Carbone AC, Singh S, Hardwicke JT. Complications of sentinel lymph node biopsy for melanoma-A systematic review of the literature. Eur J Surg Oncol. 2017;43:270-277

'Moody JA, Botham SJ, Dahill KE, Wallace DL, Hardwicke JT. Complications following completion lymphadenectomy versus therapeutic lymphadenectomy for melanoma - A systematic review of the literature. Eur J Surg Oncol. 2017;43:1760-1767

procedures for non-metastatic skin melanoma [2], thus patient management and prognosis can benefit from quality control and standardization of such procedures $[4,5]$.

The strengths of this study included the prospective collection of data in a national registry, the multicenter design and the standardized definitions of the complications [11]. The study has some limitations. First, a considerable number of centers were excluded due to poor completeness of data. Although this approach allowed limiting the impact of low-quality data on the study results, the representativeness of the included centers may be limited. Future developments will aim to achieve adequate completeness of data in the excluded centers and will implement regular audits. Second, the occurrence on skin graft failure after WE could not be evaluated due to the nonnegligible number of unfilled forms. This limitation can be addressed by future improvements regarding information exchange among surgical centers involved in patient care.

\section{Conclusion}

Our findings contribute to available literature in setting up the recommended standards for melanoma centers, thus improving the quality of surgery offered to patients. Such quality indicators can be used by other hospitals to direct quality improvement efforts.

\section{Supplementary Information}

The online version contains supplementary material available at https://doi. org/10.1186/s12885-020-07705-4.

Additional file 1: Supplementary Figure 1. Flow-chart of patient inclusion in wide excision (WE) analysis. Supplementary Figure 2. Flowchart of patient inclusion in sentinel lymph node biopsy (SLNB) analysis. Supplementary Figure 3. Flow-chart of patient inclusion in radical lymph node dissection (LFND) analysis.

\section{Abbreviations}

WE: Wide excision; SLNB: Sentinel lymph node biopsy; LFND: Radical lymph node dissection; IMI: Italian Melanoma Intergroup; CNMR: Clinical National Melanoma Registry; GDP: Gross domestic product

\section{Acknowledgements}

The authors would like to thank the Intergruppo Melanoma Italiano (IMI) and the Clinical Research Technology (CRT).

$\wedge$ Clinical National Melanoma Registry Study Group at the Italian Melanoma Intergroup:

ASERO SALVATORE: Azienda Ospedaliera di Rilievo Nazionale e di Alta Specializzazione Garibaldi-Nesima, Catania;italy.

BARBATI ROSANNA: ASL Roma C - Ospedale S. Eugenio, Roma, Italy. BIANCHI LUCA: Azienda Ospedaliera Universitaria Policlinico Tor Vergata, Roma, Italy.

BRUDER FRANCESCA: Ospedale Oncologico Cagliari, Cagliari, Italy. CATRICALÀ CATERINA: Istituto Dermatologico San Gallicano IRCCS - IFO, Roma; Italy.

CINIERI SAVERIO: Presidio Ospedaliero Antonio Perrino, Brindisi, Italy. DEL VECCHIO MICHELE: Fondazione I.R.C.C.S. Istituto Nazionale dei Tumori, Milano,Italy.

DI FILIPPO FRANCO: Istituto Nazionale Tumori Regina Elena IRCCS - IFO, Roma, Italy.

FARGNOLI MARIA CONCETTA: Presidio Ospedaliero San Salvatore, L' Aquila, Italy.

FIERRO MARIA TERESA: A.O.U. Città della Salute e della Scienza - P.O. San Lazzaro, Torino, Italy.

FORCIGNANÒ ROSACHIARA: Azienda Ospedaliera Vito Fazzi, Lecce, Italy. 
GUIDOBONI MASSIMO: I.R.S.T. Istituto Scientifico Romagnolo per lo Studio e la Cura dei Tumori, Meldola, Italy.

IACONO CARMELO: Azienda Ospedaliera Sanitaria 7 Ragusa - Ospedale Maria Paternò, Arezzo, Italy.

LOSPALLUTI LUCIA: Azienda Sanitaria Locale BA - Ospedale di Venere, Bari,Italy.

MAIO MICHELE: Azienda Ospedaliera Universitaria Senese Ospedale Le Scotte, Siena;ttaly.

MILESI LAURA: Azienda Ospedaliera Papa Giovanni XXIII, Bergamo, Italy MOISE GIANMICHELE: Azienda per i Servizi Sanitari n² Isontina Ospedale di Gorizia Dipartimento di Medicina, Gorizia, Italy.

MORETTI GIOVANNA: Azienda Ospedaliera Ospedali Riuniti PapardoPiemonte, Messina, Italy.

PELLICANO RICCARDO: IRCCS Casa Sollievo della Sofferenza, San Giovanni Rotondo: Italy.

PIZZICHETTA MARIA ANTONIETTA: Centro di Riferimento Oncologico, Istituto Nazionale Tumori, Aviano,Italy.

RINALDI GAETANA: Azienda Ospedaliera Universitaria Policlinico `Paolo Giaccone, Palermo, Italy.

SANNA GIOVANNI: Azienda Ospedaliero-Universitaria di Sassari, Sassari, Italy. STAIBANO STEFANIA: Azienda Ospedaliera Universitaria Federico II di Napoli, Napoli;italy.

VISINI MARILENA: A.O. di Lecco Presidio Ospedaliero Alessandro Manzoni, Lecco,ltaly.

ZANNETTI GUIDO: Azienda Ospedaliero-Universitaria di Bologna Policlinico S. Orsola -Malpighi, Bologna,ltaly.

ZICHICHI LEONARDO: Azienda Sanitaria Provinciale - Presidio Ospedaliero di Trapani, Trapani, Italy.

\section{Authors' contributions}

Study concepts: PDF, FC, SM, AV. Study design: PDF, FC, SM, AV, CRR. Data acquisition: PDF, FC, RS, MTC, GT, VDG, GG, PQ, MG, CF, GT, LM, MO, AT, IS, CC, PA. Quality control of data and algorithms: PDF, FC. Data analysis and interpretation: PDF, FC, SM, AS. Statistical analysis: FC. Manuscript preparation: PDF, FC, SM, AS. Manuscript editing: PDF, FC, SM. Manuscript review: SM, AB, CRR. All authors contributed to manuscript revision, read, and approved the submitted version.

\section{Funding}

The CNMR was supported by the grants received from Bristol Myers Squibb (New York, NY, USA), GlaxoSmithKline (Brentford, UK) and Pierre Fabre Pharma.

\section{Availability of data and materials}

The datasets generated and analysed during the current study are available on Mendeley Data.

Del Fiore, Paolo (2020), "Morbidity melanoma data", Mendeley Data, V2, doi: https://doi.org/10.17632/vt2n4kwb25.2 https://doi.org/10.17632/ vt2n4kwb25.2

\section{Ethics approval and consent to participate}

The study was approved by the Ethics Committee of Veneto Institute of Oncology (approval No. CESC-IOV 2011/17) on 03 February 2015. All procedures performed in studies involving human participants were in accordance with the 1964 Helsinki declaration and its later amendments or comparable ethical standards. Written informed consent was obtained from all individual participants included in the study.

\section{Consent for publication}

Not applicable.

\section{Competing interests}

The authors declare that they have no competing interests.

\section{Author details}

${ }^{1}$ Surgical Oncology Unit, Veneto Institute of Oncology IOV - IRCCS, Padova, Italy. ${ }^{2}$ Department of Surgery, Oncology and Gastroenterology (DISCOG), University of Padua, Padova, Italy. ${ }^{3}$ Division of Melanoma, Sarcoma and Rare Tumors, IRCCS, European Institute of Oncology, Milan, Italy. ${ }^{4}$ Department of Melanoma and Cancer Immunotherapy, Istituto Nazionale Tumori IRCCS Fondazione Pascale, Naples, Italy. ${ }^{5}$ Department of Dermatology, Santa Maria degli Angeli Hospital, Pordenone, Italy. ${ }^{6}$ Section of Dermatology, Department of Health Sciences, University of Florence, Florence, Italy. ${ }^{7}$ Division of Plastic and Reconstructive Surgery and Burn Unit, University of Bari, Bari, Italy. ${ }^{8}$ Division of Medical Oncology for Melanoma, Sarcoma, and Rare Tumors, IEO, European Institute of Oncology IRCCS, Milan, Italy. ${ }^{9}$ Section of Dermatology, Department of Medical Sciences and Public Health, University of Cagliari, Cagliari, Italy. ${ }^{10}$ Medical Oncology Unit, Santa Croce and Carle Teaching Hospital, Cuneo, Italy. ${ }^{11}$ Pathology, ASST-Lariana, Ospedale Sant'Anna, Como, Italy. ${ }^{12}$ DSM-Department of Medical Sciences, University of Trieste, Trieste, Italy. ${ }^{13}$ Unit of General Surgery, San Pio X Hospital, Milan, Italy. ${ }^{14}$ Department of Dermatology, Fondazione IRCCS Policlinico San Matteo, 27100 Pavia, Italy. ${ }^{15}$ Department of Cardiological, Thoracic and Vascular Sciences, and Public Health, University of Padova, Padova, Italy.

${ }^{16}$ Independent Statistician, Solagna, Italy. ${ }^{17}$ National Cancer Institute Fondazione G. Pascale, SC Chirurgia Melanoma e dei Tumori Cutanei, Naples, Italy. ${ }^{18}$ Unit of Surgical Oncology of the Esophagus and Digestive Tract, Veneto Institute of Oncology IOV-IRCCS, Padua, Italy.

Received: 15 June 2020 Accepted: 1 December 2020

Published online: 05 January 2021

\section{References}

1. Bray F, Ferlay J, Soerjomataram I, Siegel RL, Torre LA, Jemal A. Global cancer statistics 2018: GLOBOCAN estimates of incidence and mortality worldwide for 36 cancers in 185 countries. CA Cancer J Clin. 2018;68:394-424. https:// doi.org/10.3322/caac.21492.

2. Ross Ml, Gershenwald JE. Evidence-based treatment of early stage melanoma. J Surg Oncol. 2011;104:341-53. https://doi.org/10.1002/jso.21962.

3. Swetter SM, Tsao H, Bichakjian CK, Curiel-Lewandrowski C, Elder DE, Gershenwald JE, Guild V, Grant-Kels JM, Halpern AC, Johnson TM, Sober AJ, Thompson JA, Wisco OJ, Wyatt S, Hu S, Lamina T. Guidelines of care for the management of primary cutaneous melanoma. J Am Acad Dermatol. 2019; 80:208-50. https://doi.org/10.1016/j.jaad.2018.08.055.

4. Sullivan $\mathrm{R}$, Alatise $\mathrm{Ol}$, Anderson $\mathrm{BO}$, et al. Global cancer surgery: delivering safe, affordable, and timely cancer surgery. Lancet Oncol. 2015;16:1193-224. https://doi.org/10.1016/S1470-2045(15)00223-5.

5. Merkow RP, Bilimoria KY, Ko CY. Surgical quality measurement: an evolving science. JAMA Surg. 2013;148:586-7. https://doi.org/10.1001/jamasurg.2013. 128.

6. Pasquali S, Sommariva A, Spillane AJ, Bilimoria KY, Rossi CR. Measuring the quality of melanoma surgery - highlighting issues with standardization and quality assurance of care in surgical oncology. Eur J Surg Oncol. 2017;43: 561-71. https://doi.org/10.1016/j.ejso.2016.06.397.

7. Pasquali S, Spillane A. Contemporary controversies and perspectives in the staging and treatment of patients with lymph node metastasis from melanoma, especially with regards positive sentinel lymph node biopsy. Cancer Treat Rev. 2014;40:893-9. https://doi.org/10.1016/j.ctrv. 2014.06.008.

8. Bilimoria KY. Moving beyond guidelines to ensure high-quality cancer care in the United States. J Oncol Pract. 2012;8:e67-8. https://doi.org/10.1200/ JOP.2012.000686.

9. Rossi CR, Mozzillo N, Maurichi A, Pasquali S, Macripò G, Borgognoni L, Solari N, Piazzalunga D, Mascheroni L, Giudice G, Mocellin S, Patuzzo R, Caracò C, Ribero S, Marone U, Santinami M. Number of excised lymph nodes as a quality assurance measure for lymphadenectomy in melanoma. JAMA Surg. 2014;149:700-6. https://doi.org/10.1001/jamasurg.2013.5676.

10. Sommariva A, Clemente C, Rossi CR. Standardization and quality control of surgical treatment of cutaneous melanoma: looking for consensus of the Italian melanoma intergroup. Eur J Surg Oncol. 2015;41:148-56. https://doi. org/10.1016/j.ejso.2014.07.035.

11. U.S. Department of Health and Human Services (2010) Common terminology criteria for adverse events v4.03 (CTCAE). http://evs.nci.nih.gov/ ftp1/CTCAE/CTCAE_4.03_2010-06-14_QuickReference_5x7.pdf.

12. R Core Team. $R$ : a language and environment for statistical computing. In: $R$ Foundation for statistical computing. Vienna; 2018. URL https://www.Rproject.org/.

13. Morton DL, Cochran AJ, Thompson JF, Elashoff R, Essner R, Glass EC, Mozzillo N, Nieweg OE, Roses DF, Hoekstra HJ, Karakousis CP, Reintgen DS, Coventry BJ, Wang HJ, Multicenter Selective Lymphadenectomy Trial Group. Sentinel node biopsy for early-stage melanoma: accuracy and morbidity in 
MSLT-I, an international multicenter trial. Ann Surg. 2005;242(3):302-11; discussion 311-3. https://doi.org/10.1097/01.sla.0000181092.50141.fa.

14. Moody JA, Ali RF, Carbone AC, Singh S, Hardwicke JT. Complications of sentinel lymph node biopsy for melanoma - a systematic review of the literature. Eur J Surg Oncol. 2017;43:270-7. https://doi.org/10.1016/j.ejso. 2016.06.407.

15. Moody JA, Botham SJ, Dahill KE, Wallace DL, Hardwicke JT. Complications following completion lymphadenectomy versus therapeutic

lymphadenectomy for melanoma - a systematic review of the literature. Eur J Surg Oncol. 2017;43:1760-7. https://doi.org/10.1016/j.ejso.2017.07.003.

16. Gheorghe A, Moran G, Duffy H, Roberts T, Pinkney T, Calvert M. Health utility values associated with surgical site infection: a systematic review. Value Health. 2015;18(8):1126-37.

17. Brusaferro S, Arnoldo L, Finzi G, Mura I, Auxilia F, Pasquarella C, Agodi A, Board; Group. Hospital Hygiene and Infection Prevention and Control in Italy: state of the art and perspectives. Ann Ig. 2018;30(5 Supple 2):1-6. https://doi.org/10.7416/ai.2018.2245.

18. Hernandez-Boussard T, Downey JR, McDonald K, Morton JM. Relationship between patient safety and hospital surgical volume. Health Serv Res. 2012; 47(2):756-69. https://doi.org/10.1111/j.1475-6773.2011.01310.x Epub 2011 Aug 30

\section{Publisher's Note}

Springer Nature remains neutral with regard to jurisdictional claims in published maps and institutional affiliations.

Ready to submit your research? Choose BMC and benefit from:

- fast, convenient online submission

- thorough peer review by experienced researchers in your field

- rapid publication on acceptance

- support for research data, including large and complex data types

- gold Open Access which fosters wider collaboration and increased citations

- maximum visibility for your research: over $100 \mathrm{M}$ website views per year

At BMC, research is always in progress.

Learn more biomedcentral.com/submissions 